\title{
Alimentos transgênicos: Benefícios, malefícios e controvérsias
}

\author{
Transgenic foods: Benefits, harms and disputes \\ Alimentos transgénicos: Beneficios, daños y disputas
}

Recebido: 08/12/2021 | Revisado: 13/12/2021 | Aceito: 14/12/2021 | Publicado: 21/12/2021

\author{
Bárbara Maciel de Barros \\ ORCID: https://orcid.org/0000-0001-6045-0757 \\ Centro Universitário de Brasília, Brasil \\ E-mail: barbarabarros2@hotmail.com \\ Bruna Moura de Oliveira \\ ORCID: https://orcid.org/0000-0001-8338-4529 \\ Centro Universitário de Brasília, Brasil \\ E-mail: bumouraoliveira@gmail.com \\ Maria Cláudia da Silva \\ ORCID: https://orcid.org/0000-0001-7172-8064 \\ Centro Universitário de Brasília, Brasil \\ E-mail: mariaclaudianut@gmail.com
}

\begin{abstract}
Resumo
O consumo de alimentos transgênicos aumentou nas últimas duas décadas, a partir de alterações genéticas produzidas em laboratórios, através de técnicas artificiais de engenharia genética em plantas, animais e microorganismos. Baseado nisto, este trabalho utilizou a metodologia de revisão bibliográfica para se entender melhor a respeito deste consumo. De acordo com os artigos pesquisados os organismos transgênicos não trazem mal para a saúde humana, a fim de ter uma menor quantidade de agrotóxicos em seus alimentos, ajudando no processo de conservação e produção de suas plantações. Concluindo-se que os alimentos transgênicos estão trazendo mais benefícios do que malefícios para a população.
\end{abstract}

Palavras-chave: Transgênicos; Malefícios e benefícios; Segurança alimentar; Transgênicos e meio ambiente; Transgênicos e saúde; Agrotóxico.

\begin{abstract}
The consumption of transgenic foods has increased in the last two decades, from genetic alterations produced in laboratories, through artificial techniques of genetic engineering in plants, animals and microorganisms. Based on this, this work used the literature review methodology to better understand this consumption. According to the articles researched, transgenic organisms do not harm human health, in order to have a lower amount of pesticides in their food, helping in the conservation and production process of their plantations. Concluding that transgenic foods are bringing more benefits than harm to the population.
\end{abstract}

Keywords: Transgenics; Harm and benefits; Food safety; Transgenics and the environment; Transgenics and health; Pesticides.

\section{Resumen}

El consumo de alimentos transgénicos se ha incrementado en las últimas dos décadas, desde alteraciones genéticas producidas en laboratorios, pasando por técnicas artificiales de ingeniería genética en plantas, animales y microorganismos. En base a esto, este trabajo utilizó la metodología de revisión de la literatura para comprender mejor este consumo. Según los artículos investigados, los organismos transgénicos no dañan la salud humana, con el fin de tener una menor cantidad de pesticidas en sus alimentos, ayudando en el proceso de conservación y producción de sus plantaciones. Concluyendo que los alimentos transgénicos están aportando más beneficios que daños a la población.

Palabras clave: Transgénicos; Daños y beneficios; Seguridad alimentaria; Transgénicos y medio ambiente; Transgénicos y salud; Pesticidas.

\section{Introdução}

Os transgênicos são organismos geneticamente modificados (OGMs) com alteração do código genético (DNA) e produzidos em laboratórios por meio de técnicas artificiais de engenharia genética, realizados com plantas, animais e microorganismos (IDEC,2019). O transgênico foi uma inovação da biotecnologia e engenharia genética formada pela Revolução Verde, na década de 1996, nos Estados Unidos (Silva et al., 2020). 
Para a engenharia genética e a biotecnologia, esses alimentos podem ser a solução para a fome no mundo. Segundo Bongaarts, citado por Zanettini e Pasquali (1998), em 2050 a população duplicará e a tecnologia de produção agrícola atual não será suficiente para alimentar todos. Demonstra-se que a sociedade mundial está precisando de uma solução para sanar esse problema de falta e má distribuição de alimentos. (Zanettini e Pasquali,1998).

Segundo dados da Embrapa, a cada 100 hectares plantados com soja hoje no mundo, 80 são de sementes com genes alterados. No caso do milho, são 30 para cada 100. A área com culturas transgênicas subiu 100 vezes, de 1,7 milhões de hectares para 175,2 milhões. O primeiro país a liderar o plantio são os Estados Unidos, seguidos pelo Brasil e Argentina. E até hoje, a utilização dos transgênicos gera polêmicas relacionadas aos possíveis riscos à saúde e ao meio ambiente, possíveis benefícios e limitações (Embrapa, 2021).

Algumas das principais características dos alimentos transgênicos são, melhor rendimento e produtividade, resistência a pragas, preservação da biodiversidade, ecossistemas e sustentabilidade, com maior quantidade e qualidade dos alimentos, menor custo e menor área de cultivo. Por outro lado, ainda existem incertezas relacionadas aos riscos à saúde humana como, alergias alimentares, resistência a antibióticos, aumento das substâncias tóxicas, maior quantidade de agrotóxico nos alimentos consumidos e ainda, a falta de informação nos rótulos das embalagens (Embrapa, 2021; Ventura et al, 2020).

Diante do exposto, este estudo tem por objetivo, analisar os possíveis malefícios e os benefícios dos alimentos transgênicos segundo a literatura, fazendo com que as pessoas saibam o que estão consumindo.

\section{Metodologia}

Neste estudo foi realizada uma revisão bibliográfica sobre os benefícios e malefícios dos alimentos transgênicos. Com base nos artigos científicos acerca do tema em pesquisa, foi realizado uma revisão através do dados Google Acadêmico, SciELO, Embrapa, jornal Brazilian Journal, Genética vegetal, ScienceDirect, OMS, publicados nos últimos anos na língua portuguesa e na língua inglesa.

Os termos utilizados para a busca dos artigos foram identificados nos descritores de alimentos transgênicos, riscos dos alimentos transgênicos, insegurança alimentar, benefícios dos transgênicos, transgenic food, disadvantagens, controvérsias OGM, agrotóxicos. Dessa forma, foi contemplada uma visão ampla desses alimentos, enfocando a segurança e os riscos ao consumidor e ao meio ambiente.

Foram considerados como critérios de inclusão os artigos científicos, publicados nos últimos 20 anos, nos idiomas português e inglês referentes ao tema: Alimentos transgênicos: benefícios, malefícios e controvérsias.

Quanto aos critérios de exclusão: artigos científicos em idioma diferente do incluso, publicações anteriores ao ano referido e artigos com datas mais antigas por ter sido encontrados pesquisas mais atuais com conteúdos semelhantes.

\section{Resultados e Discussão}

Os artigos selecionados serão analisados de forma a entender os objetivos e conhecimentos sobre o tema proposto como, avaliação de riscos à saúde humana e meio ambiente, os benéficos na agricultura, as informações necessárias ao consumidor e como esse tipo de alimento é produzido.

\section{Históricos e Conceitos dos Transgênicos}

A palavra transgênico é sinônimo para a expressão "Organismo Geneticamente Modificado" (OGM). É um organismo que recebe um gene de outro organismo doador e essa alteração no seu DNA permite que mostre uma característica que não 
tinha antes. Na natureza, sempre ocorreram (e ainda ocorrem) alterações ou mutações naturais por meio da Engenharia Genética (Embrapa, 2021).

A partir de 1970, com os conhecimentos sobre material genético, DNA e suas propriedades, proporcionam o emprego de técnicas relacionadas à transferência de genes específicos entre espécies diferentes. Assim, essa tecnologia recebeu o nome de Engenharia Genética e as plantas modificadas, denominadas transgênicas (Almeida e Lamounier, 2005).

Com o processo de globalização, as empresas multinacionais, que tinham a capacidade de criar e cultivar plantas geneticamente modificadas, impactaram o setor agrícola brasileiro. Dessa forma, com a promulgação da Lei de Proteção de Cultivares (Lei no 9457/1997) e aprovação da Lei no 10.814/2003 que permite a liberação comercial de OGMs, as pesquisas sobre esses alimentos cresceram e várias empresas mudaram a base genética para cultivares transgênicas, investindo em técnicas biotecnológicas. (Almeida \& Lamounier, 2005)

Essas técnicas biotecnológicas tem como objetivo encontrar formas para minimizar a fome, problemas climáticos, aumentar o rendimento com uso reduzido de terra e de custos e promover a segurança alimentar com menos produtos químicos e maior qualidade dos alimentos. (Almeida \& Lamounier, 2005)

Para produzir uma planta transgênica é necessário uma série de etapas, com pesquisas que envolvem cientistas de diversas áreas do conhecimento. A Figura 1 apresenta o resumo da produção das plantas geneticamente modificadas.

Figura 1 - Esquema com resumo da produção de uma planta transgênica.

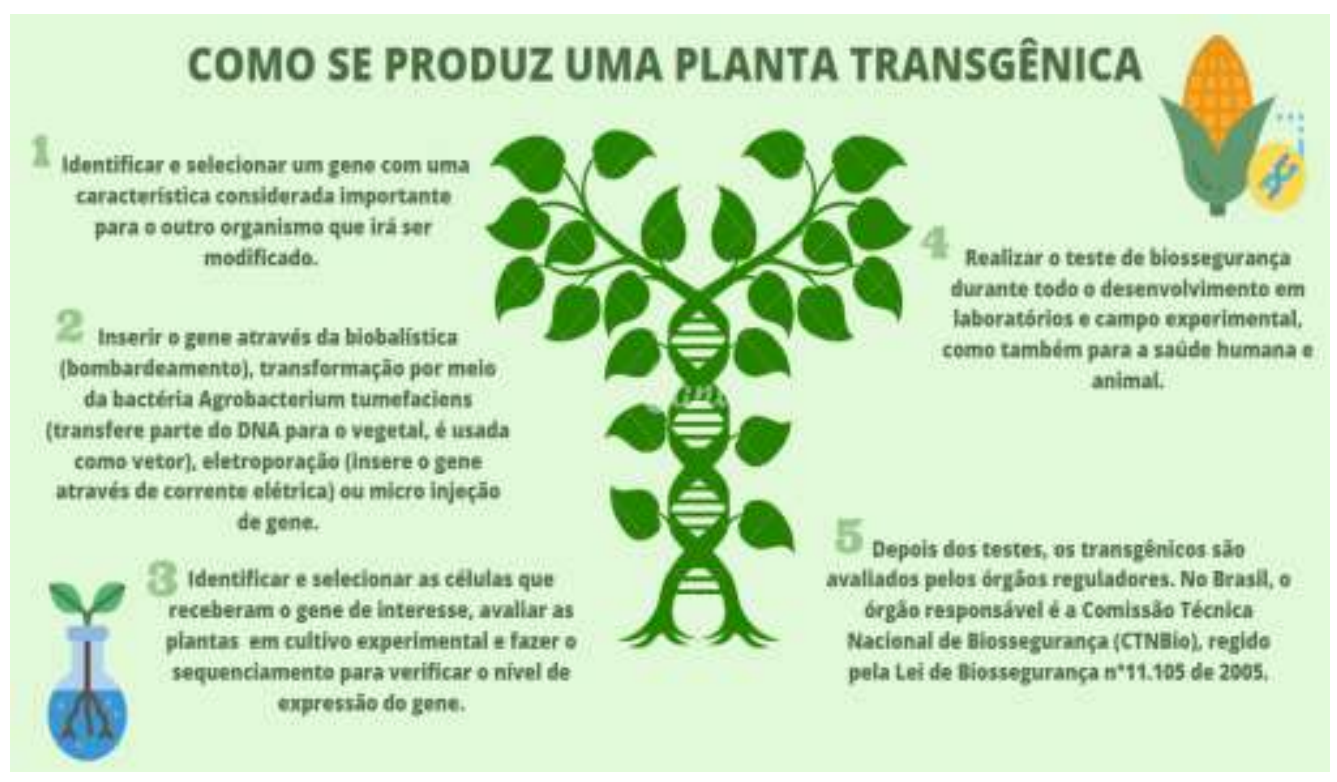

Fonte: Croplife Brasil (2020).

\section{Alimentos transgênicos na saúde humana e no ambiente}

Os alimentos transgênicos são produzidos há anos com o objetivo de beneficiar a agricultura, os indivíduos e combater a fome. Mas, percebe-se que as informações sobre esses alimentos não são feitas de forma clara para a população. As pessoas consomem, porém não têm conhecimento sobre o que estão consumindo (Pedrancini et al, 2008).

Esse tipo de alimento ainda é muito discutido, por também abranger assuntos como produção, liberação comercial, comercialização, biossegurança, direito do consumidor, experimentos em laboratórios e rotulagem. Comer ou não comer alimentos transgênicos, desenvolver ou reproduzir não é tão simples, existe uma grande quantidade de argumentos sobre esse 
desenvolvimento tecnológico. Mas as vantagens desses alimentos são claras e precisas, não podem ser ignoradas por dúvidas sobre os riscos, é preciso pesquisas, estudos e cautela em relação aos problemas que irão surgir (Zhang et al., 2016).

Dentre as vantagens conhecidas, estão melhor controle ambiental com a redução ou extinção do uso de agrotóxico, proporciona maior velocidade na geração de novos cultivos, melhoria nas qualidades dos produtos agrícolas e contribui para a diminuição ou extinção da fome fornecendo fontes nutricionais. Dessa forma, os alimentos podem ser mais nutritivos, com maior durabilidade de armazenamento, sendo produzidos por meio de tecnologia, de forma econômica e reduzindo problemas relacionados à desnutrição. O que, pode beneficiar, por exemplo, a melhora na deficiência de vitamina $\mathrm{A}$, iodo e ferro, onde segundo o Ministério da Saúde, uma em cada três pessoas é afetada pela deficiência desses micronutrientes (Valois, 2001; Ministério da saúde, 2007).

Outros benefícios dos transgênicos, são uma maior produção e produtividade de plantas de outras espécies com plantas anãs, resistentes a fungos, vírus e bactérias evitando devastações na agricultura. Além disso, aproveitamento de áreas marginais se adaptando em diversas condições naturais e reduzindo problemas de doenças que seriam tratadas com fármacos e vacinas a partir de plantas transgênicas (Valois, 2001).

Da mesma forma que existem muitas dúvidas sobre os malefícios dos alimentos transgênicos, há discussões também sobre a rotulagem desses produtos. De acordo com O Código de Defesa do Consumidor é obrigatório ao direito do consumidor que os produtos expostos no mercado não irão causar riscos à saúde ou segurança do consumidor, os fornecedores são obrigados a permitir as informações dos produtos, de forma clara e legível. Mesmo se tendo toda a informação completa dos componentes do produto ainda se tem dúvidas na população, por falta de conhecimento das consequências do produto, tanto para o consumidor, quanto para o meio ambiente (Silva \& Cachapuz, 2007).

Em todo produto transgênico se tem um símbolo com a letra "T" envolta por um triângulo com o fundo amarelo, para diferenciá-lo dos demais, logo no painel principal do rótulo, como as expressões, nem sempre são usadas, "produto transgênico", "contém produto transgênico(s)" ou "contém ingrediente produzido a partir de produto transgênico". Mesmo com as expressões, ainda é preciso colocar a imagem do símbolo transgênico para informar o consumidor sobre a origem e composição do produto (Silva \& Cachapuz, 2007). Conhecer o que está comprando e entender o que está sendo informado é de grande importância para o consumidor. Além disso, as informações devem ser corretas, claras e confiáveis, o que compete à Agência Nacional de Vigilância Sanitária (ANVISA) garantir a fiscalização e a legislação desses produtos.

A Organização das Nações Unidas para Alimentação e Agricultura (FAO) e a Organização Mundial da Saúde (OMS), monitoram com inúmeros testes laboratoriais e pesquisas sobre transgênicos e mesmo com a legislação e estudos rigorosos, existem dúvidas e preconceito sobre o seu consumo e segurança alimentar. Algo muito questionado é se os transgênicos são mesmo seguros, porém, nenhuma pesquisa comprovou que esse tipo de alimento possa causar doenças no ser humano ou prejuízo ao meio ambiente (Embrapa,2021).

\section{Controvérsias sobre transgênicos}

Considerando as normas do Ministério da Saúde, a maior preocupação com os alimentos transgênicos é o fato de não ser totalmente comprovado cientificamente, que é um alimento seguro, quando se modifica os genes de um organismo para o outro, irá manter a boa qualidade e preservação do alimento e não trazendo problemas à saúde da população (Silva et al., 2020).

Os principais motivos que levam os cientistas e/ou órgãos oficiais a serem contra a produção de transgênicos estão relacionados às incertezas quanto é prejudicial à saúde humana, animal e ao meio ambiente. Os riscos podem ser pela contaminação genética da biodiversidade, onde sementes transgênicas podem ameaçar o cultivo de sementes crioulas, 
contaminando os cultivares convencionais com pólen transgênicos levados pela chuva, vento e insetos (Araújo \& Mercadante, 1999).

Outro aspecto discutido contrário ao uso de transgênicos seria a possibilidade do desenvolvimento de resistência de insetos a inseticidas, com o uso contínuo de elevadas dosagens de inseticidas ou bioinseticidas, que agem de um mesmo modo, há um aumento da resistência com o passar das gerações da praga reduzindo a eficiência do controle de inseticidas. Isso vai exigir uma maior quantidade de agrotóxicos nas plantações poluindo rios e solos. Além disso, o elevado uso de agroquímicos, a compactação de solos e o uso de diesel polui o meio ambiente, prejudicando também, a microfauna, bactérias e seres vivos presentes no solo e na água (Lazzarini, 2007).

Em relação aos riscos à saúde humana, o efeito alergênico, devido a novos compostos que se formam em alimentos modificados podem ser fatais, bem como a existência de uma possível alteração no metabolismo humano. O que reforça a importância da rotulagem nutricional, monitoramento e aplicações contínuas de segurança dos alimentos geneticamente modificados (Araújo \& Mercadante, 1999).

Segundo a Lei Brasileira de Biossegurança (11.105/05), que estabelece as atividades com transgênicos e de Biotecnologia, afirma que um produto transgênico para ser comercializado é obrigado a passar por aproximadamente 10 anos de estudos. Apenas vai para o mercado depois de examinado e aprovado pela CTNBio, onde cada produto geneticamente modificado é avaliado por especialistas de várias áreas científicas para garantir uma atividade legal e legítima, regida por legislação específica e pautada por rígidos critérios de biossegurança. Dessa forma, esses estudos garantem a segurança alimentar e ambiental (Embrapa, 2021).

Diante das controvérsias existentes é importante salientar que a OMS e a FAO, avaliaram o protocolo para testes em alimentos geneticamente modificados e não foi detectado nenhum tipo de efeito alérgico em relação a esses alimentos atualmente no mercado. Em relação aos agrotóxicos, mesmo que a planta transgênica carregue um gene resistente a algum inseto, outros produtos terão que ser usados para combater plantas daninhas sendo o alimento transgênico ou não. Além disso, os agrotóxicos geram maiores custos para o agricultor, ou seja, é vantajoso utilizar apenas o necessário para proteger a lavoura de pragas e doenças. Mesmo com o alto consumo de alimentos transgênicos, não há nenhum registro de impacto negativo no meio ambiente ou na saúde de humanos e animais (OMS, 2014; Syngenta, 2021).

\section{Produtos geneticamente modificados comercializados no mundo e no Brasil}

Os produtos geneticamente modificados começaram a ser produzidos para ter uma melhora na adaptação e uma maior produtividade, a biotecnologia moderna teve uma grande evolução de variedades técnicas, procedimentos e processos, com isso a tecnologia do DNA recombinante passou a ser aplicada nos alimentos e dessa forma pode substituir ou complementar a biotecnologia clássica (Costa et al., 2003).

Os alimentos transgênicos recebem este nome por serem geneticamente modificados em laboratório com adição de um gene de outra espécie para ganhar alguma característica favorável. No caso da soja, o gene vem de uma bactéria que deixa a planta mais resistente ao herbicida mais usado na agricultura. Esses produtos geneticamente modificados são uma das principais inovações da agricultura mundial e são comercializados buscando melhores alternativas para a sua produção (Miranda et al., 2017)

As primeiras plantas transgênicas foram desenvolvidas na China na década de 1990, nos Estados Unidos a primeira aprovação do uso de transgênicos foi em 1994, quando a empresa Calgene lançou um tomate com resistência a longos períodos de armazenamento. O Brasil está em segundo lugar em plantação de transgênicos em culturas de soja, mandioca, arroz, milho, algodão, cana de açúcar e canola, sendo o segundo maior produtor mundial de soja, atrás apenas dos Estados Unidos. Dessa 
forma, os fatores que determinaram a permanência e o crescimento da produção de soja no mercado foi por ser um grão com fonte de óleo vegetal comestível, o farelo utilizado na ração animal e o alto valor protéico para a nutrição humana (Azevedo et al., 2000).

Segundo os dados mais recentes da Consultoria Spark smarter decisions, especialista em informações para o agronegócio, a safra de 2019/2020, apresentou crescimento no uso de sementes de milho transgênico e estabilidade para as outras duas culturas, como representado na Figura 2.

Figura 2 - Porcentagem das plantas cultivadas no Brasil e o aumento da produtividade em 2019/2020.

\section{ADOÇÃO DE PLANTAS OGM NO BRASIL}

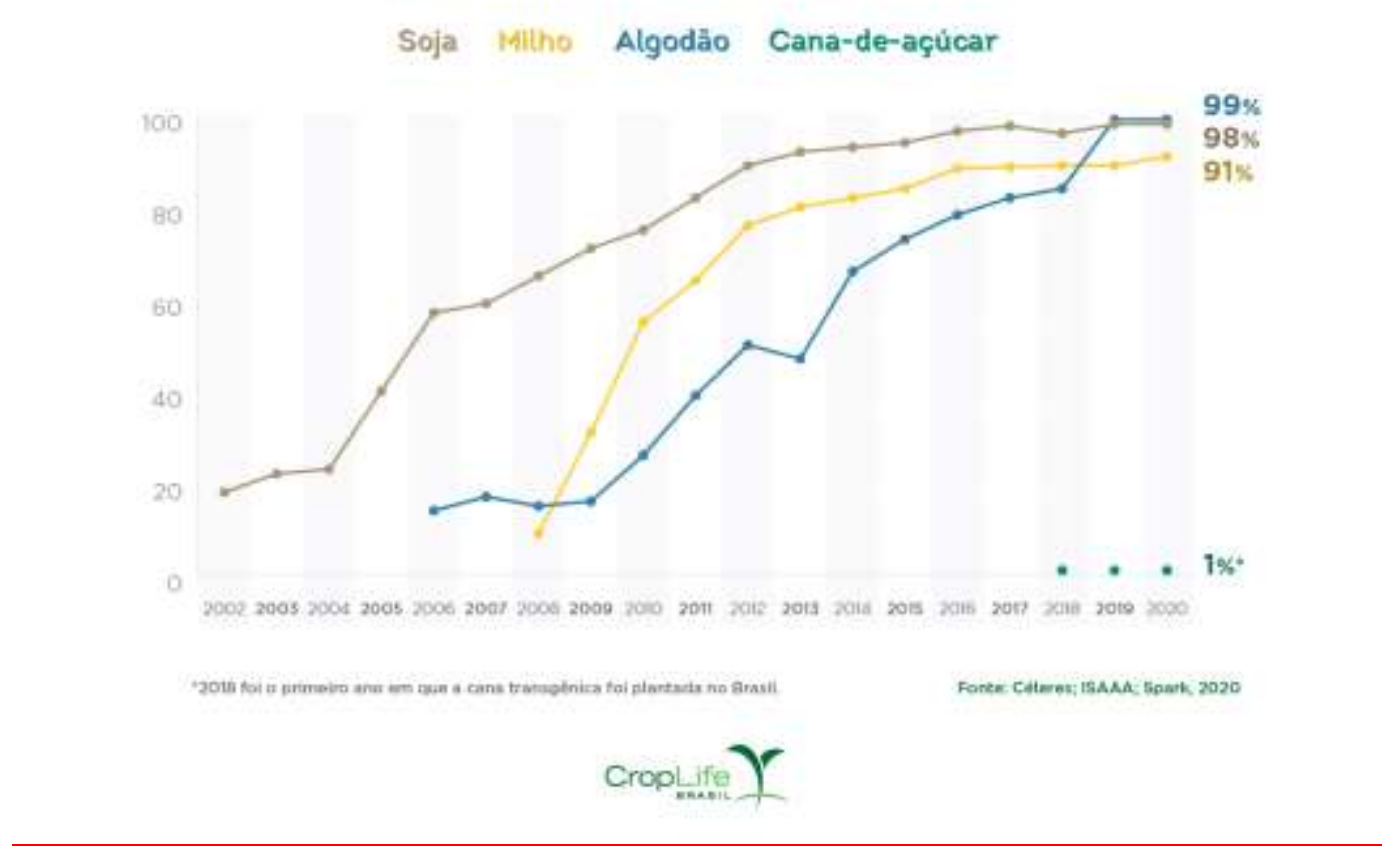

Fonte: CropLife Brasil (2020).

Devido ao alto potencial produtivo, o mundo passou a cultivar plantas transgênicas como: milho, batata, melão, berinjela, beterraba, pimentão, mamão, ameixa, entre outros, aumentando cada vez mais produtos ou derivados de produtos transgênicos na alimentação. Além disso, as plantas não são os únicos alimentos geneticamente modificados, existem produtos, que em sua maioria, não são totalmente transgênicos, mas apresentam em sua composição alguma porcentagem mínima de algum Organismo Geneticamente Modificado (OGM) considerado transgênico. No entanto, no Brasil, apenas as variedades de soja, milho, algodão e cana-de-açúcar são cultivadas para produção de alimentos (Croplife, 2020). Diante disto muitos produtos industrializados possuem diversas variedades de transgênicos como ingredientes, alguns exemplos apresentados na Figura 3. 
Figura 3 - Alimentos que podem conter ingredientes transgênicos.

\section{ALIMENTOS PRODUZIDOS COM INGREDIENTES TRANSGÊNICOS}
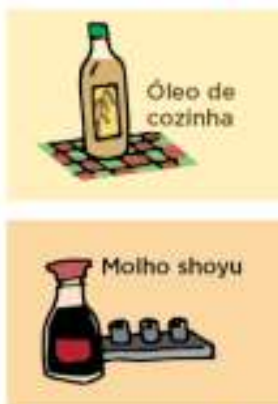
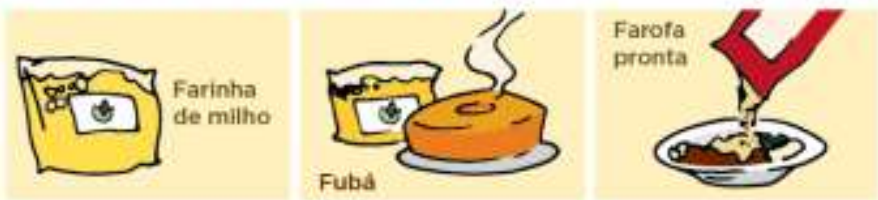

Proteina texturizada

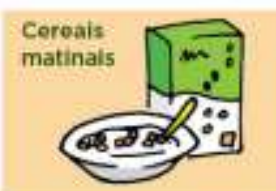

Fubs
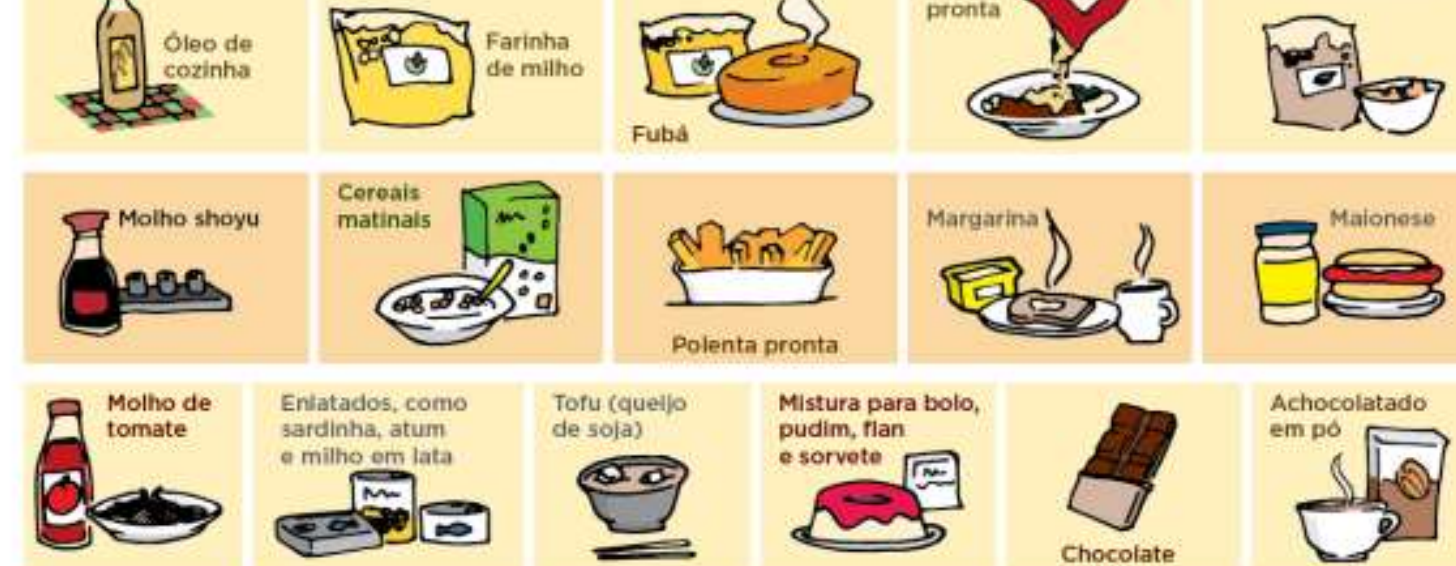

Guloseimas, como balas e chicletes
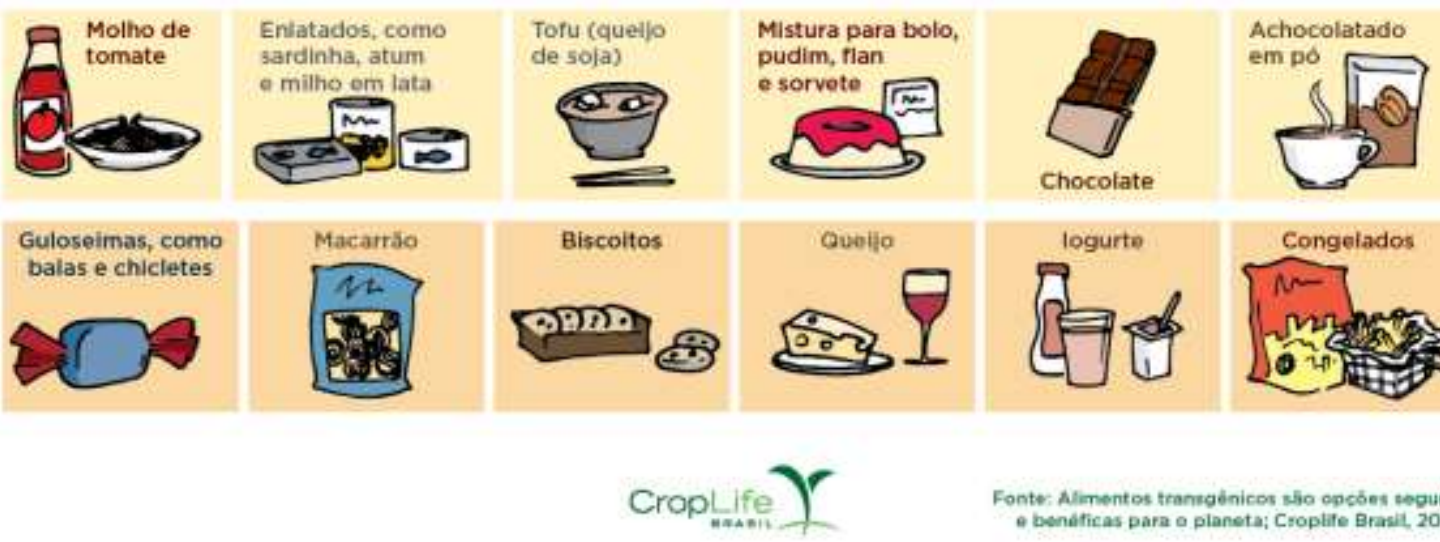

Fonte: Alimentos tranugínicos sło opobes seguras
o benáficas para a planeta; Croplife Brasil 2020 .

Fonte: CropLife Brasil (2020).

\section{Aspectos políticos, sociais econômicos que podem ser afetados pela utilização de transgênicos}

Os alimentos transgênicos vêm ocupando grande espaço no mundo, mas ainda assim com dúvidas, discussões, manifestações e proibições, para o poder executivo, legislativo e judiciário, até então existem dúvidas e posicionamento a respeito dos transgênicos. Dessa forma, depois de muitos desacordos, foi aprovada a Lei de Biossegurança, n. 11.105/2005, que regulamenta como será a liberação das sementes transgênicas no meio ambiente, liberando a produção, comercialização e plantio. Em países que são contra o cultivo e consumo dos transgênicos, tem como argumentos que falta embasamento científico, capazes de comprovar que esses produtos não oferecem riscos à saúde e nem prejuízos à natureza (Silva, 2006).

Com isso, para os produtores rurais, essa nova tecnologia é um grande avanço na produtividade e aumento dos lucros. Além de ministros e deputados da república serem contra os alimentos geneticamente modificados, houve também manifestações contra a liberação e a venda desses alimentos por algumas entidades representativas (CIB, 2018; Ventura et al, 2020).

Por motivo de serviço dobrado o número de vagas de trabalho aumentaram em 49.281 empregos nas últimas duas décadas, proporcionando ganhos na produção de alimentos transgênicos, gerando uma atividade econômica e ótima fonte de renda, promovendo os seus setores e juntamente com os fornecedores de insumos (CIB, 2018).

Devido a grande economia que os produtores de transgênicos estão tendo, está virando uma prioridade nas produções, com o intuito de ajudar as populações dos países pobres, que estão com pouco acesso, não conseguindo suprir suas necessidades, utilizando a nova tecnologia. Com o investimento em biotecnologia aumentando, está sendo um bom negócio, para a competição das empresas e melhoria de seus produtos (Momma, 2003). 


\section{Conclusão}

Existem muitas controvérsias a respeito dos malefícios e benefícios dos alimentos transgénicos aos seres humanos e ao meio ambiente. Com isso, foram selecionados artigos e percebemos que os benefícios possuem mais fundamentos que os riscos causados aos consumidores e a natureza, pois são feitos inúmeros testes laboratoriais e pesquisas definidas pela OMS e pela FAO, que asseguram o consumo e a produção legalizada desses alimentos. A maior preocupação era a quantidade de agrotóxicos que são usados nesses alimentos, porém podemos ver que a quantidade é menor do que a dos alimentos que não são transgênicos.

Quanto ao processo de rotulagem, é necessário destacar a importância de informações completas e claras, para que o consumidor compreenda e tenha a opção de escolher o que deseja consumir, visto que as plantas não são os únicos alimentos modificados, existem vários produtos que apresentam uma porcentagem de organismos geneticamente modificados em sua formação.

Dessa forma, é inevitável e fundamental que exista um controle rigoroso e devida fiscalização sobre os produtos transgênicos, juntamente com campanhas educacionais para que a população tenha mais informação e consciência do que está consumindo. Dessa forma é possível diminuir as dúvidas e ter mais conhecimentos gerais sobre todos os produtos que são fabricados, independente de serem transgênicos ou não.

\section{Referências}

Almeida, G. C. S. \& Lamounier, W. M. (2005). Os alimentos transgênicos na agricultura brasileira: evolução e perspectivas. Organizações Rurais \& Agroindustriais. 7(3), 345-355. https://www.redalyc.org/pdf/878/87817135008.pdf

Araújo, C. J. \& Mercadante, M. (1999) Produtos transgênicos na agricultura. Biblioteca Digital da Câmara dos Deputados, Câmara dos Deputados, Praça 3 Poderes Consultoria Legislativa, Anexo III - Térreo Brasília - DF, abril/1999. https://bd.camara.leg.br/bd/bitstream/handle/bdcamara/1311/pr odutos_transgenicos_cordeiro.pdf?sequence=5\&isAllowed=y.

Azevedo, J. L. de, Fungaro, M. H. P., \& Vieira, M. L. C. (2000). Transgênicos e evolução dirigida. História, Ciências, Saúde-Manguinhos, 7 , 451-464. https://doi.org/10.1590/S0104-59702000000300014.

base.digital. (n.d.). Alimentos transgênicos são opções seguras e benéficas para o planeta. CropLife Brasil. https://croplifebrasil.org/noticias/alimentostransgenicos/

Conselho de informações sobre biotecnologia - CIB. (2018). 20 anos de transgênicos: impactos ambientais, econômicos e sociais no Brasil. Agroconsult Consultoria e Projetos. https://agroavances.com/img/publicacion_documentos/153575459920-anos-de-transgenicos-no-brasil.pdf.

Costa, J., Matté, R. G. Kist, A. \& Matté, M. H. (2003). Alimentos geneticamente modificados: aspectos regulatórios e de saúde pública. Revista de Direito Sanitário, 4(3). https://www.revistas.usp.br/rdisan/article/view/81064/84713

Sobre o tema - Portal Embrapa. (n.d.). www.embrapa.br. https://www.embrapa.br/tema-transgenicos/sobre-o-tema

Lazzarini, M., \& Lazzarini, A. (2004). Os Transgênicos e os Riscos à Saúde. Cadernos Do Programa de Pós-Graduação Em Direito - PPGDir./UFRGS, 2(5). https://doi.org/10.22456/2317-8558.49562

Básica, A. Cadernos De.https://bvsms.saude.gov.br/bvs/publicacoes/cadernos_atencao_basica_carencias_micronutrientes.pdf

Martinez, D., Cunha, A., Augusto, C., Rangel, V., \& Capilé, H. (n.d.). (2021) A cultura da soja transgênica no Brasil. https://web.archive.org/web/20180430133326id_/http://www.revista.universo.edu.br/index.php?journal=2013EAD1\&page=article\&op=viewFile\&path\%5B\% $5 \mathrm{D}=3579 \&$ path $\% 5 \mathrm{~B} \% 5 \mathrm{D}=2229$

Monquero, P. A. (2005). Plantas transgênicas resistentes aos herbicidas: situação e perspectivas. Bragantia, 64, 517-531. https://doi.org/10.1590/S000687052005000400002

Pedrancini, V. D., Corazza-Nunes, M. J., Galuch, M. T. B., Moreira, A. L. O. R., \& Nunes, W. M. de C. (2008). Saber científico e conhecimento espontâneo: opiniões de alunos do ensino médio sobre transgênicos. Ciência \& Educação (Bauru), 14, 135-146. https://doi.org/10.1590/S1516-73132008000100009

Cachapuz, R. da R., \& Silva, G. H. R. (2007). A rotulagem dos alimentos transgênicos - direito do consumidor e aspecto fundamental da personalidade. Revista Jurídica Cesumar - Mestrado, 7(1), 119-136. https://periodicos.unicesumar.edu.br/index.php/revjuridica/article/view/519/377

Silva, M. S., Lima, F. L. O., Silva, C. D. C. M., \& Silva, M. V. C. M. (2020). Alimentos transgênicos e segurança alimentar e nutricional no Brasil / Transgenic foods and food and nutritional security in Brazil. Brazilian Journal of Health Review, 3(5), 11901-11923. https://doi.org/10.34119/bjhrv3n5-046

Hugo, G., \& Silva, R. (2006). Centro Universitário De Maringá Programa De Pós-Graduação Em Ciências Jurídicas Alimentos Transgênicos -Direito Do Consumidor E Aspecto Fundamental Da Personalidade Maringá. http://www.dominiopublico.gov.br/download/teste/arqs/cp025596.pdf 
Research, Society and Development, v. 10, n. 17, e86101724543, 2021

(CC BY 4.0) | ISSN 2525-3409 | DOI: http://dx.doi.org/10.33448/rsd-v10i17.24543

Alimentos transgênicos fazem mal à saúde? (2020). Syngenta. https://www.syngenta.com.br/alimentos-transgenicos-fazem-mal-saude

Celso, A., \& $\quad$ Valois, C. (2001). Importância Dos Transêenicos Para A Agricultura. 1, 27-53. https://ainfo.cnptia.embrapa.br/digital/bitstream/item/204035/1/Importancia-dos-transgenicos-para-a-agricultura.pdf

Universidade Federal De Santa Maria Centro De Ciências Naturais E Exatas -CCNE Departamento De Biologia Disciplina De Genética Agronomia. (n.d.). (2021). http://w3.ufsm.br/geneticavegetal/images/anexos/textosgenetica/Texto\%209\%20-\%20Plantas\%20transg\%C3\%AAnicas.pdf

Organização mundial da saúde. (2014). Alimentos, geneticamente modificados. https://www.who.int/news-room/q-a-detail/food-genetically-modified.

Ventura, M. V. A., Batista, H. R. F., Bessa, M. M., Pereira, L. S., Costa, E. M., \& Oliveira, M. H. R. de. (2020). Comparison of conventional and transgenic soybean production costs in different regions in Brazil. Research, Society and Development, 9(7), e154973977-e154973977. https://doi.org/10.33448/rsdv9i7.3977

Zhang, C., Wohlhueter, R., \& Zhang, H. (2016). Alimentos geneticamente modificados: Uma revisão crítica de suas promessas e problemas. ScienceDirect, Food Science and Human Wellness, 5(3). 116-123. https://doi.org/10.1016/j.fshw.2016.04.002 